\title{
Seismic Performance Assessment of a Conventional Multi-storey Building
}

\author{
Giuseppe Marcantonio Del Gobbo $^{1} \cdot$ Martin S. Williams $^{1} \cdot$ Anthony Blakeborough $^{1}$
}

Published online: 30 August 2017

(c) The Author(s) 2017. This article is an open access publication

\begin{abstract}
Recent earthquakes have revealed that conventional seismic design philosophy allows for large levels of nonstructural damage. Nonstructural earthquake damage results in extensive repair costs and lengthy functional disruptions, as nonstructural systems comprise the majority of building investment and are essential to building operations. A better understanding of the expected overall seismic performance of code-compliant buildings is needed. This study investigates the seismic performance of a conventional building. A 16-storey steel office building was designed using a modern seismic structural code (Eurocode 8). This study is the first to assess in detail the substantial earthquake repair costs expected in a modern Eurocode concentric braced frame structure, considering nonstructural systems with the FEMA P-58 procedure. The breakdown of total repair costs by engineering demand parameter and by fragility group is novel. The seismic performance assessment indicated that substantial earthquake repair costs are expected. Limitations of the Eurocode nonstructural damage methodology were revealed in a novel manner using FEMA P-58, as the prescribed drift limits did not minimize nonstructural repair costs. These findings demonstrate the need for design procedures that improve nonstructural seismic performance. The study results provide a benchmark on which to evaluate retrofit alternatives for existing buildings and design options for new structures.
\end{abstract}

Giuseppe Marcantonio Del Gobbo giuseppe.delgobbo@eng.ox.ac.uk

1 Department of Engineering Science, University of Oxford, Oxford OX1 3PJ, UK
Keywords Eurocode $8 \cdot$ FEMA P-58 - Nonstructural systems $\cdot$ Seismic performance assessment

\section{Introduction}

Recent earthquakes such as the 2010 Canterbury earthquake and the 2010 Chile earthquake have demonstrated that buildings that incur minimal structural damage frequently experience extensive nonstructural damage (Dhakal 2010; Miranda et al. 2012). Nonstructural systems refer to building contents, architectural components, and mechanical, electrical and plumbing systems. These systems are essential to building functions and comprise the majority of building investment (Fig. 1). Nonstructural damage results in lengthy functional disruptions and accounted for several billion dollars of losses in 2010 alone (Fierro et al. 2011).

Attaining a target level of seismic performance mandates the harmonization of structural and nonstructural performance levels. An improved understanding of the expected structural and nonstructural seismic performance of conventional code-compliant buildings is therefore needed. This study assesses the seismic performance of a structural design that is representative of conventional buildings constructed in seismic regions. The results of the performance assessment provide a benchmark on which to evaluate retrofit alternatives for existing buildings or design options for new structures.

A case study building was designed to represent conventional structures in seismic regions. A finite element model of the design was created in OpenSees (PEER 2015) to determine the nonlinear response of the structure. Two suites of ground motion records were compiled to represent the earthquake intensities of interest. A FEMA P-58 (ATC 


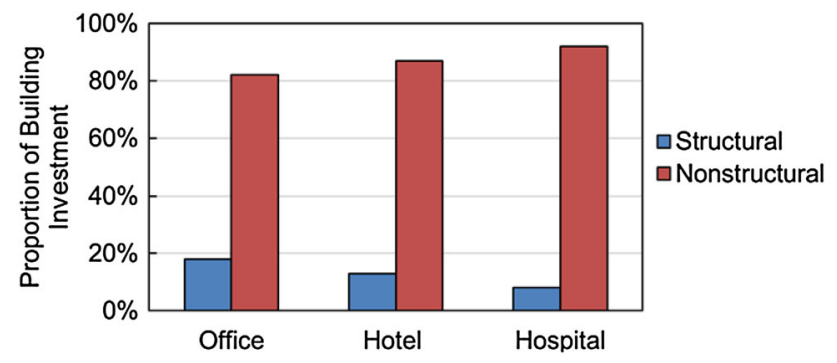

Fig. 1 Typical structural and nonstructural investment proportions for three building uses Source: Data from Taghavi and Miranda (2003)

2012) building performance model was produced to convert the structural analysis results into probable seismic performance. Nonlinear time history analyses of the finite element model were conducted using the ground motion suites. The results of the seismic performance assessment were calculated and analyzed.

\section{Design of the Case Study Building}

A Eurocode-compliant (CEN 2010) building design was created to represent structures designed in a conventional manner. By evaluating the seismic performance of the case study building, conclusions can be inferred about the seismic performance of conventional structures with similar designs. It is useful for an example of possible structural and nonstructural damage distributions to be determined in detail.

The case study structure is a 16-storey steel office building. The lateral load resisting system consists of concentric braced frames (CBFs) located around the perimeter of the structure. Seismic design forces were obtained through modal response spectrum analysis of the structure in SAP2000 (CSI 2013). A peak ground acceleration (PGA) of $0.31 \mathrm{~g}$ was used for the design, representing a location with significant earthquakes. This PGA is bounded by the two strongest seismic zones in Greece and in Turkey (Solomos et al. 2008). Medium sand (ground class C) was assumed (CEN 2013). The first period of the building $\left(T_{1}\right)$ is $2.34 \mathrm{~s}$. An elevation and a plan view are shown in Fig. 2. The building sections are shown in Table 1.

\section{Model of the Case Study Building}

A 2D model of the structure was created in the finite element program OpenSees (PEER 2015). This model will allow nonlinear analysis of the structure to be performed. A leaning column was employed to account for P-Delta
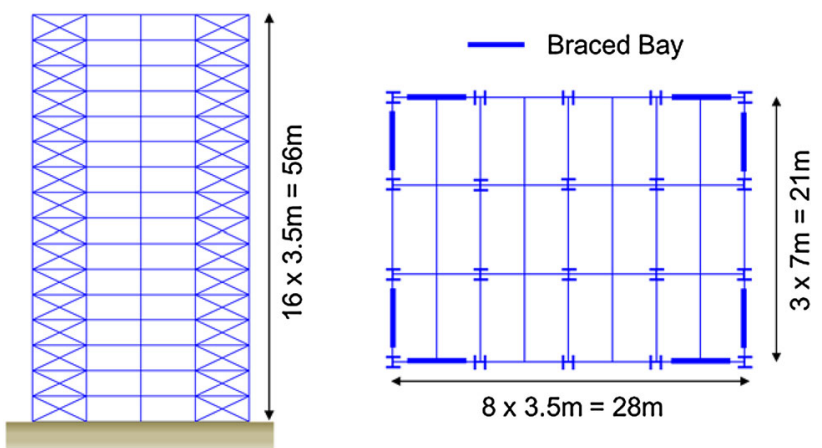

Fig. 2 Elevation and plan views of the 16-storey case study steel office building

Table 1 Column and brace steel sections of the 16-storey case study building

\begin{tabular}{|c|c|c|c|}
\hline \multirow[t]{2}{*}{ Storey } & \multicolumn{2}{|l|}{ Column (UKC) } & \multirow[t]{2}{*}{ Brace (SHS) } \\
\hline & Exterior & Corner & \\
\hline 16 & $203 \times 203 \times 71$ & $203 \times 203 \times 71$ & $140 \times 140 \times 5$ \\
\hline 15 & $203 \times 203 \times 71$ & $203 \times 203 \times 71$ & $140 \times 140 \times 5$ \\
\hline 14 & $203 \times 203 \times 100$ & $203 \times 203 \times 100$ & $140 \times 140 \times 5$ \\
\hline 13 & $203 \times 203 \times 100$ & $203 \times 203 \times 100$ & $140 \times 140 \times 5$ \\
\hline 12 & $254 \times 254 \times 132$ & $254 \times 254 \times 167$ & $140 \times 140 \times 6.3$ \\
\hline 11 & $254 \times 254 \times 132$ & $254 \times 254 \times 167$ & $140 \times 140 \times 6.3$ \\
\hline 10 & $305 \times 305 \times 198$ & $305 \times 305 \times 198$ & $140 \times 140 \times 6.3$ \\
\hline 9 & $305 \times 305 \times 198$ & $305 \times 305 \times 198$ & $140 \times 140 \times 8$ \\
\hline 8 & $305 \times 305 \times 240$ & $305 \times 305 \times 240$ & $140 \times 140 \times 8$ \\
\hline 7 & $305 \times 305 \times 240$ & $305 \times 305 \times 240$ & $140 \times 140 \times 8$ \\
\hline 6 & $305 \times 305 \times 283$ & $356 \times 406 \times 287$ & $140 \times 140 \times 10$ \\
\hline 5 & $305 \times 305 \times 283$ & $356 \times 406 \times 287$ & $140 \times 140 \times 10$ \\
\hline 4 & $305 \times 406 \times 340$ & $356 \times 406 \times 393$ & $140 \times 140 \times 10$ \\
\hline 3 & $305 \times 406 \times 340$ & $356 \times 406 \times 393$ & $140 \times 140 \times 12.5$ \\
\hline 2 & $356 \times 406 \times 393$ & $356 \times 406 \times 467$ & $140 \times 140 \times 12.5$ \\
\hline 1 & $356 \times 406 \times 393$ & $356 \times 406 \times 467$ & $140 \times 140 \times 12.5$ \\
\hline
\end{tabular}

UKC UK column, SHS structural hollow section

effects from vertical loads acting on gravity columns in the tributary plan area. Inherent damping of 5\% was represented using mass proportional and tangent stiffness proportional Rayleigh damping. The first and third periods were used to determine the Rayleigh damping parameters as these modes account for $92 \%$ of the effective mass. The first period was elongated to account for anticipated brace buckling, mitigating the generation of artificial damping forces (Charney 2008).

As the lateral load resisting system of the structure is $\mathrm{CBFs}$, the behavior of the braces will control the response of the building during earthquakes. It is therefore necessary to accurately model the brace behavior. The braces were 
modelled using the procedure proposed by Uriz et al. (2008). Each brace was modelled using two elements with an initial imperfection of $0.1 \%$ at the midspan to induce buckling in compression. A fictitious load producing $5 \%$ of the section yield moment was applied at the midspan to prevent brace straightening. The analytical model was verified using experimental data from Black et al. (1980). The validation is shown in Fig. 3, which displays the experimental and analytical results of a brace subjected to cyclic loading. Brace buckling in compression and yielding in tension are accurately predicted, capturing the hysteretic behavior.

\section{Ground Motion Scaling and Selection}

Suitable earthquake ground motion records were selected in order to investigate the seismic response of the case study building. The ground motions must be scaled to match the desired earthquake intensity. Nonlinear time history analysis of the structural model can then be performed using these ground motions. Records were obtained from the PEER ground motion database (PEER 2013).

Ground motion suites representing the ultimate limit state (ULS) and the serviceability limit state (SLS) as defined by Eurocode 8 were created. The ULS earthquake has a $10 \%$ probability of exceedance in 50 years. Structures are designed to withstand the ULS seismic action while retaining structural integrity after the earthquake. The SLS earthquake has a $10 \%$ probability of exceedance in 10 years. Damage at the SLS should be limited to a point that does not compromise building serviceability (CEN 2013).

The ground motion records were selected and scaled following the Eurocode 8 requirements (CEN 2013). A factor of 0.5 was used to define the SLS spectrum. A linear scale factor was applied to each record, which minimized the mean squared error (MSE) between the ground motion spectrum and the target Eurocode spectrum over the period range of $0.2 T_{1}$ to $2 T_{1}$. The scale factor was restricted to a

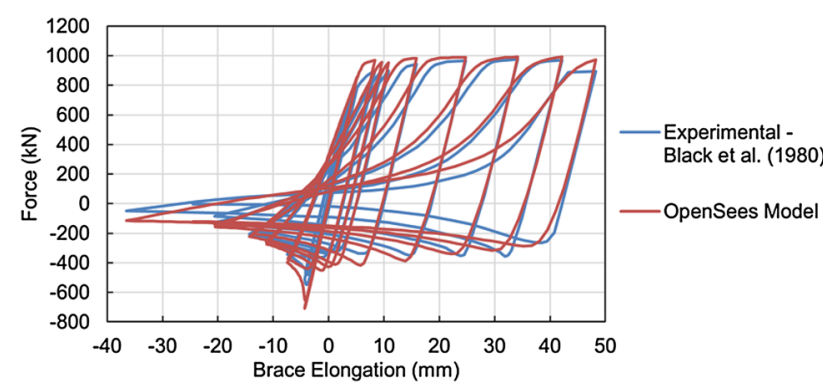

Fig. 3 Comparison of experimental and analytical brace behavior under cyclic loading maximum of 2. The MSE was calculated using Eq. (1) from PEER (2013), where $T_{i}$ is a period within the range of interest, $S A^{\text {target }}\left(T_{i}\right)$ and $S A^{\text {record }}\left(T_{i}\right)$ are the spectral accelerations at period $T_{i}$ of the target and record response spectra respectively, and $f$ is the scale factor applied to the record response spectrum.

$M S E=\sum_{i}\left[\ln \left(\frac{S A^{\text {target }}\left(T_{i}\right)}{f \times S A^{\text {record }}\left(T_{i}\right)}\right)\right]^{2}$

A maximum of one record was selected per historical earthquake. ULS ground motions were constrained to have a magnitude greater than 5.5 to match the Eurocode Type 1 spectrum and all ground motions had an average shear wave velocity appropriate for ground type C (CEN 2013). Twenty-five ground motions with the smallest MSE were selected for each suite. Figure 4 compares the ground motion suite spectrum and the Eurocode 8 elastic response spectrum for both the ULS and SLS. The period range of interest has been indicated in the figure, as well as values within one standard deviation $(\sigma)$ from the mean.

\section{Seismic Performance Assessment Procedure}

The FEMA P-58 performance assessment procedure (ATC 2012) was used to evaluate the seismic performance of the case study building. The procedure uses a building performance model to convert structural analysis results into seismic performance. Seismic performance is expressed by probable repair costs.

The FEMA P-58 building performance model is a collection of data representing the building assets at risk during an earthquake. The building assets include both structural and nonstructural systems. Normative quantities of nonstructural systems corresponding to a commercial office building were considered in this case study along with all structural components. When possible, nonstructural systems of a high seismic design category were selected to represent stringent seismic considerations.

Each type of building component is associated with fragility functions and repair cost functions. Fragility functions indicate the probability of incurring damage at a given engineering demand parameter (EDP) value. Structural response parameters used to characterize demands on structural and nonstructural systems are absolute floor acceleration, absolute floor velocity, and interstorey drift ratio (IDR). Fragility functions are typically represented by lognormal cumulative distribution functions. Several fragility functions can be defined for a component corresponding to different damage states. Repair cost functions indicate the economic losses for each damage state. 
Fig. 4 Comparison of the ground motion suite spectrum and the Eurocode 8 spectrum for the ultimate limit state (ULS, left) and the serviceability limit state (SLS, right)

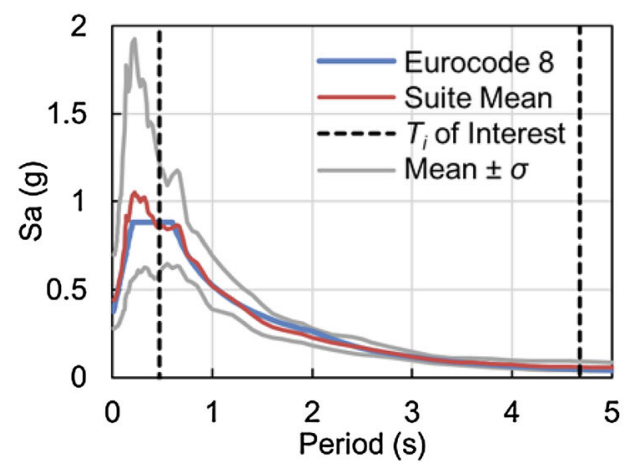

Table 2 Summary of fragility information for critical structural and nonstructural systems from FEMA P-58 (ATC 2012)

\begin{tabular}{|c|c|c|c|c|}
\hline System & EDP & Damage state & $x_{m}$ & $\beta$ \\
\hline \multirow[t]{2}{*}{ Concentric braced frame } & \multirow[t]{2}{*}{ IDR } & Brace buckling and yielding & 0.01 & 0.3 \\
\hline & & Brace fracture or local buckling & 0.0178 & 0.3 \\
\hline \multirow[t]{2}{*}{ Glass curtain wall } & \multirow[t]{2}{*}{ IDR } & Glass cracking & 0.01097 & 0.45 \\
\hline & & Glass falls from frame & 0.01254 & 0.45 \\
\hline \multirow[t]{3}{*}{ Gypsum wall partition with metal studs } & \multirow[t]{3}{*}{ IDR } & Minor cracking & 0.0021 & 0.6 \\
\hline & & Moderate cracking or crushing & 0.0071 & 0.45 \\
\hline & & Significant cracking or crushing & 0.012 & 0.45 \\
\hline \multirow[t]{3}{*}{ Suspended ceiling, vertical and lateral support } & \multirow[t]{3}{*}{ PFA } & Minor tile dislodgment & 0.35 & 0.4 \\
\hline & & Tile dislodgment and grid damage & 0.55 & 0.4 \\
\hline & & Total ceiling collapse & 0.8 & 0.4 \\
\hline Air handling unit & PFA & Equipment does not function & 0.25 & 0.4 \\
\hline Desktop electronics & PFA & Falls, does not function & 0.4 & 0.5 \\
\hline
\end{tabular}

$E D P$ engineering demand parameter, IDR interstorey drift ratio, $P F A$ peak floor acceleration, $x_{m}$ median EDP value, $\beta$ is the standard deviation of the natural logarithms

Table 2 provides a summary of the critical fragility information used in the case study from FEMA P-58 (ATC 2012).

Peak structural response parameters from the time history analyses are used in combination with fragility functions to determine damage states for the building components. Corresponding repair costs are calculated using the repair cost functions. A Monte Carlo analysis is conducted using 1000 realizations per limit state. FEMA P-58 enables the seismic performance of a structure to be measured in repair costs rather than a set of structural parameters. This is a major advantage of the procedure, as repair costs clearly communicate seismic performance and are useful for decision making.

\section{Nonlinear Time History Analysis Results}

A nonlinear time history analysis of the case study building model was conducted in OpenSees for each of the 50 ground motion records. The peak EDP values from each analysis were then extracted. The peak EDP results are shown in Fig. 5 for both the ULS and SLS. These plots include the mean values, as well as values one standard deviation from the mean. Peak absolute floor velocity results were omitted as the mean values are comparable over the building height, with a ULS mean of $4.2 \mathrm{~m} / \mathrm{s}$ and a SLS mean of $2.5 \mathrm{~m} / \mathrm{s}$.

Figure 5 shows that the ULS results have a greater spread than the SLS results. This result coincides with the significant nonlinear behavior exhibited by the braces during the larger intensity ULS earthquakes. It is also influenced by the variance of the ground motion suites.

Figure 6 compares the typical brace behavior observed during a ULS analysis and a SLS analysis. The same ground motion record of Imperial Valley-02 1940 was used. The ULS scale factor is 1.34 and the SLS scale factor is 0.68 . The selected brace is located in the 8th storey of the building. The brace exhibits predominantly elastic behavior during the SLS with the initiation of minor buckling. The brace experiences considerable nonlinear behavior during the ULS, as substantial buckling and some yielding take place. 
Fig. 5 Peak absolute accelerations (left) and peak interstorey drifts (right) determined from the time history analyses for the ultimate limit state (ULS) and serviceability limit state (SLS)
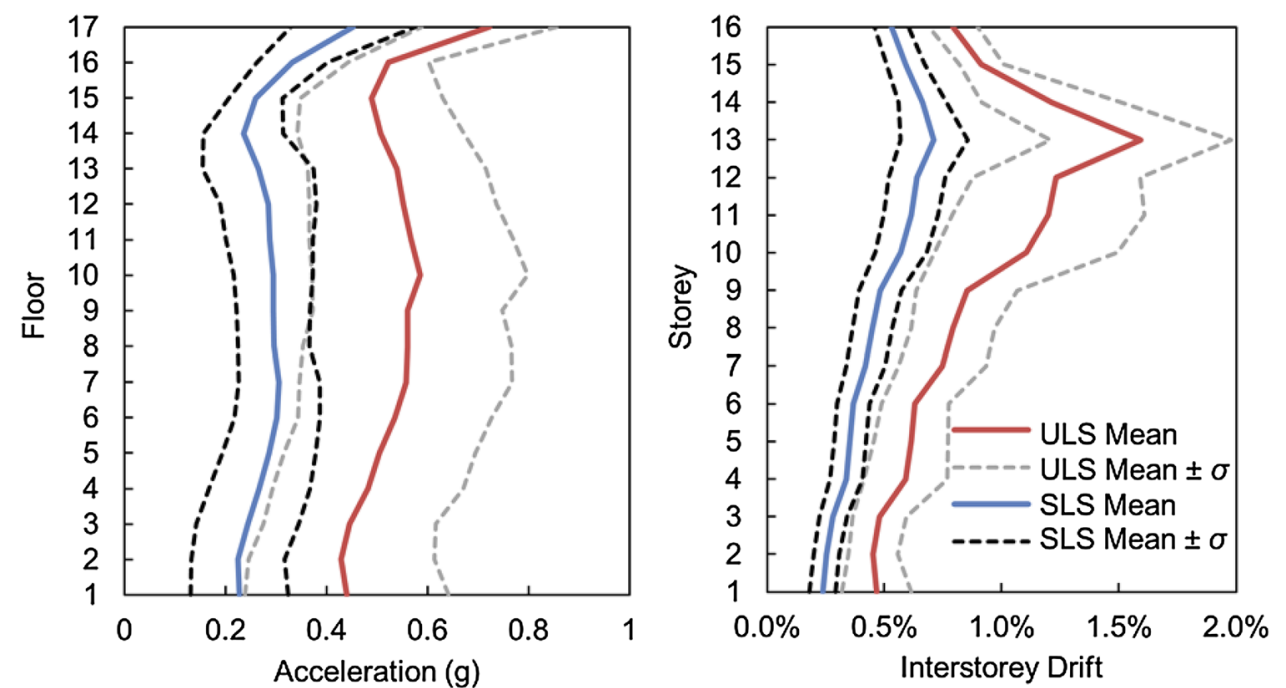

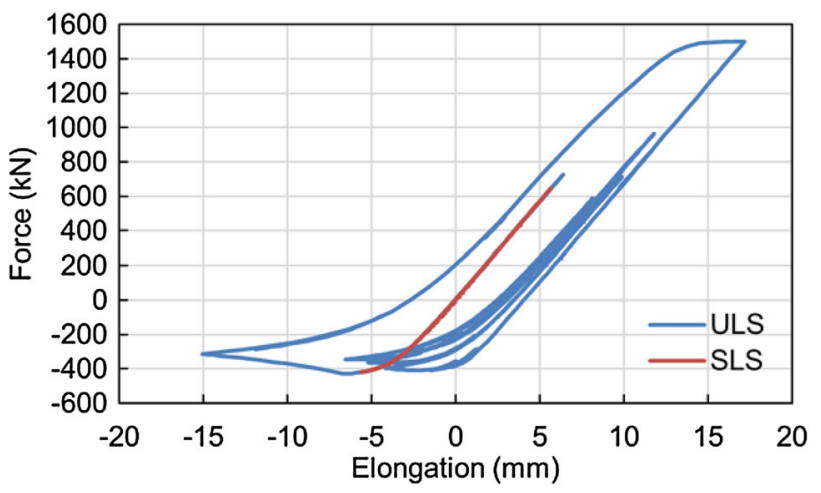

Fig. 6 Brace response during an ultimate limit state (ULS) and serviceability limit state (SLS) earthquake

\section{Seismic Performance Results}

The results of the seismic performance assessment are expressed by repair costs in 2011 US dollars. Direct repair costs resulting from damage to building assets are calculated, while indirect costs due to building downtime are out of scope. Although the indirect costs are significant, they are difficult to accurately assess for a case study building.

\subsection{Total Repair Costs}

A Monte Carlo analysis with 1000 realizations for each limit state was performed using the FEMA P-58 procedure. Cumulative distribution functions of the ULS and SLS total repair costs for the case study building are shown in Fig. 7. Each point represents one of the realizations run per limit state. The ULS repair costs are greater than the SLS repair costs, as expected, due to the difference in earthquake intensity. The spread of the ULS data is also greater, reflecting the results of the time history analyses. The

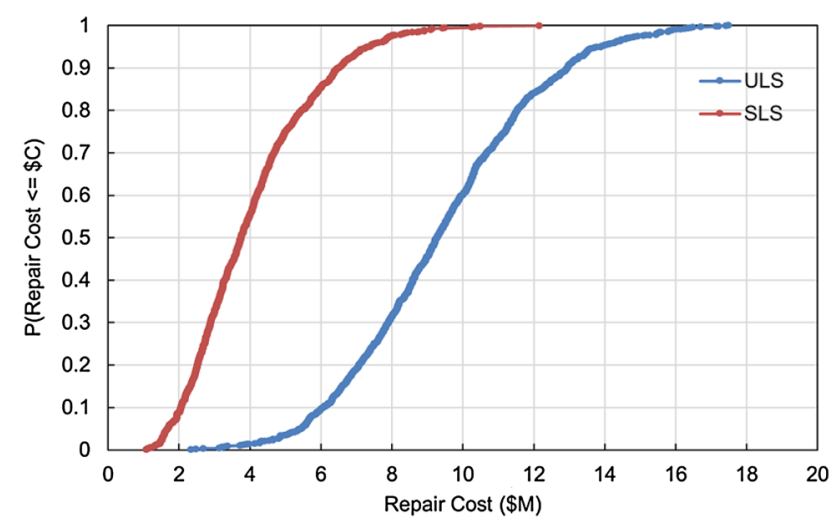

Fig. 7 Cumulative distribution functions of the ultimate limit state (ULS) and serviceability limit state (SLS) total repair costs

mean, median and 90th percentile total repair costs are shown in Table 3.

The SLS repair costs are of concern. Damage at this earthquake intensity should be limited to a level that does not compromise building serviceability (CEN 2013). However, the assessment results indicate that extensive SLS damage is expected. This suggests that modern building standards do not accomplish earthquake resilience: the ability to recover quickly after an earthquake.

Owners often elect to demolish and replace the existing building if repair costs exceed $40 \%$ of the building cost

Table 3 Total repair costs for the ultimate limit state (ULS) and serviceability limit state (SLS)

\begin{tabular}{llll}
\hline Limit state & Mean cost & Median cost & 90th percentile cost \\
\hline ULS & $\$ 9.4 \mathrm{M}$ & $\$ 9.3 \mathrm{M}$ & $\$ 12.9 \mathrm{M}$ \\
SLS & $\$ 4.0 \mathrm{M}$ & $\$ 3.7 \mathrm{M}$ & $\$ 6.5 \mathrm{M}$ \\
\hline
\end{tabular}


(ATC 2012). The total cost of the case study building was estimated to be USD 20 million following discussion with professional cost consultants. The mean and 90th percentile ULS repair costs are approximately 47 and $65 \%$ of the building cost respectively. These results imply it is probable that similar buildings designed to current structural codes may be demolished and replaced following a ULS earthquake. The implications for a city center are severe, where it can be expected that many comparable buildings will be present.

\subsection{Repair Costs Considering Engineering Demand Parameter}

Repair costs from the seismic performance assessment were grouped based on the EDP that generated the damage. The mean repair costs of the case study building considering the related EDP are shown in Fig. 8.

Figure 8 shows that acceleration-sensitive damage is comparable to drift-sensitive damage. Acceleration-sensitive damage and drift-sensitive damage comprise the majority of repair costs for both the ULS and SLS. Fiftythree percent of the ULS repair costs are drift-sensitive and $40 \%$ are acceleration-sensitive, while IDR and acceleration each account for $42 \%$ of the SLS repair costs. Conventional building codes control drifts but do not place limitations on allowable floor accelerations. Accelerations are only taken into account for calculations of anchorage strength. The influence of acceleration on seismic performance should be more appropriately reflected in the design procedures of structures.

In order to further investigate the relationship between EDPs and repair costs, mean repair costs were calculated for each floor in the case study building. Floor repair costs classified by the associated EDP are displayed in Fig. 9 for the ULS and SLS. Floor one indicates the ground floor and floor 17 indicates the roof.

The repair costs shown in Fig. 9 have a similar distribution for both the ULS and SLS. Large repair costs are

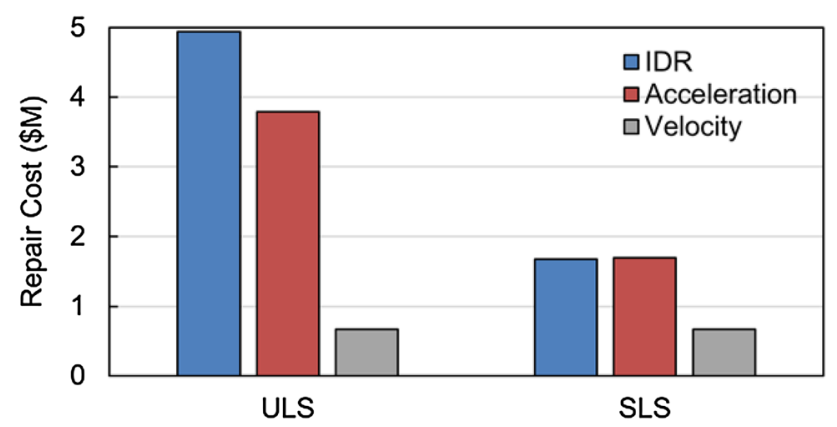

Fig. 8 Mean repair costs grouped by associated engineering demand parameter (EDP); IDR interstorey drift ratio, $U L S$ ultimate limit state, $S L S$ serviceability limit state indicated on floor one, with the majority attributed to acceleration. This is due to a concentration of accelerationsensitive nonstructural components on the ground floor such as heating, ventilating and air conditioning (HVAC) equipment. Floor 17 exhibits minimal damage as there are few components located on the roof of the building.

The remaining floors (2-16) are office occupancy and have similar nonstructural and structural quantities. The levels of acceleration-sensitive and velocity-sensitive repair costs on each office floor are comparable. This is in accordance with the time history analysis results in which the peak velocities and accelerations were similar for floors two to 16. The difference in repair costs at these floors is predominantly controlled by drift-sensitive costs. The distribution of drift-sensitive costs correlates with the mean IDR results from the time history analyses. For example, floor 13 exhibits the maximum IDR repair cost as well as the maximum mean IDR.

\subsection{Repair Costs Considering Fragility Group}

The total repair cost for the building is the sum of the damage experienced by all fragility groups. For each fragility group, the repair cost is a function of the damage state experienced by each component, the replacement cost per component, and the number of components in the group. The mean repair costs were arranged by the responsible structural and nonstructural fragility groups. This disaggregation is shown in Fig. 10.

Figure 10 indicates that significant repair costs are produced by the fragility groups of structural components, glass curtain wall cladding, wall partitions, suspended ceilings, HVAC equipment, and office equipment. Fragility groups with negligible contributions to repair costs are stairs, access flooring, elevators, piping, fire sprinkler systems, and electrical systems. Future seismic performance studies may exclude the fragility groups with negligible repair costs in order to decrease the required computation time.

Investigating the ULS distribution in Fig. 10 reveals that the structural system has the greatest repair cost of the fragility groups. The structural system accounts for $26 \%$ of the total repair cost. Brace damage is responsible for the majority of this cost. Structural damage is anticipated for the ULS event, as conventional seismic design relies on structural members experiencing inelastic deformations. These large inelastic deformations are concentrated in members designed to dissipate seismic energy in a controlled manner. Although the inelastic deformations damage the structural members, life safety of building occupants is achieved. Nonstructural systems are often omitted or treated in an oversimplified manner during the design of a structure. However, $74 \%$ of the ULS repair 
Fig. 9 Ultimate limit state (ULS, left) and serviceability limit state (SLS, right) mean repair costs at each floor per engineering demand parameter (EDP); IDR interstorey drift ratio
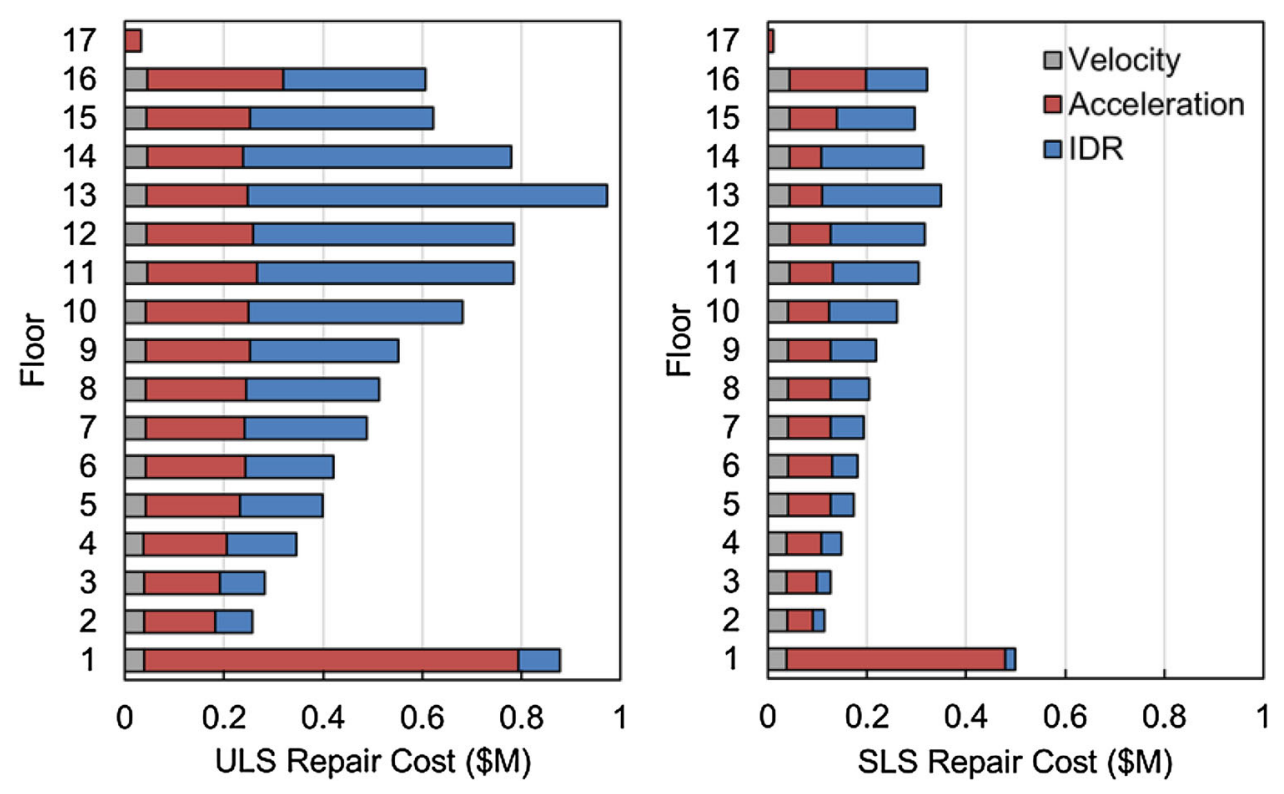

Fig. 10 Mean repair costs arranged by fragility group for the ultimate limit state (ULS) and serviceability limit state (SLS); HVAC heating, ventilating and air conditioning

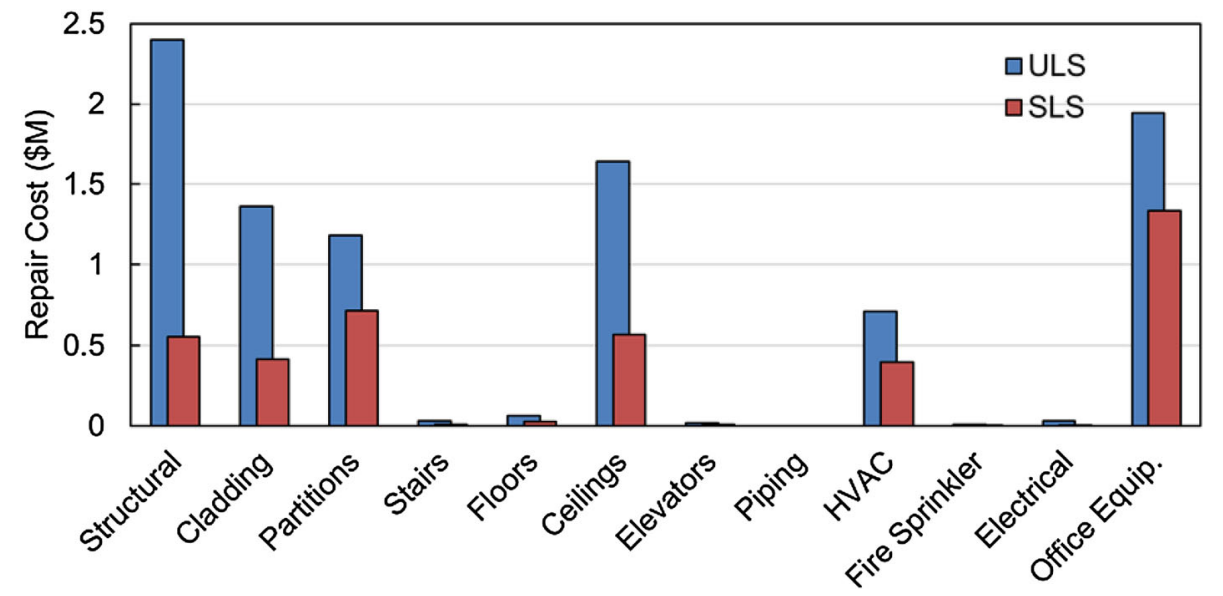

costs can be attributed to these systems. This demonstrates the need to consider nonstructural systems during structural design.

Figure 10 indicates that the case study building experiences structural damage during the SLS event. Structural damage would introduce significant delays to building reoccupancy. Nonstructural systems account for $87 \%$ of the SLS repair costs. Office equipment such as desktop electronics is the largest contributor, followed by wall partitions and suspended ceilings. Significant repair costs can therefore be expected for comparable modern multi-storey structures following a serviceability level earthquake. These results highlight the importance of considering nonstructural seismic performance when designing for a rapid return to building occupancy. Attaining a target level of seismic performance mandates the harmonization of structural and nonstructural performance levels.

\section{Eurocode Nonstructural Provisions}

The case study exposed limitations of the Eurocode 8 damage mitigation methodology. Eurocode $8 \mathrm{Cl} 4.4 .3$ (CEN 2013) provides damage limitation requirements as drift limits based on the nonstructural systems of the building. Multiple limits are specified to minimize structural and nonstructural damage. The most stringent requirement to protect nonstructural systems is a maximum allowable interstorey drift of $0.5 \%$ during the SLS (CEN 2013). Serviceability is expected at $0.5 \%$ drift according to the methodology.

The $0.5 \%$ drift limit was inadequate in preventing damage to drift-sensitive nonstructural systems in the case study building. The SLS mean drifts of storeys one to nine were within the allowable limit, however these storeys still experienced nonstructural damage. Figure 11 demonstrates 


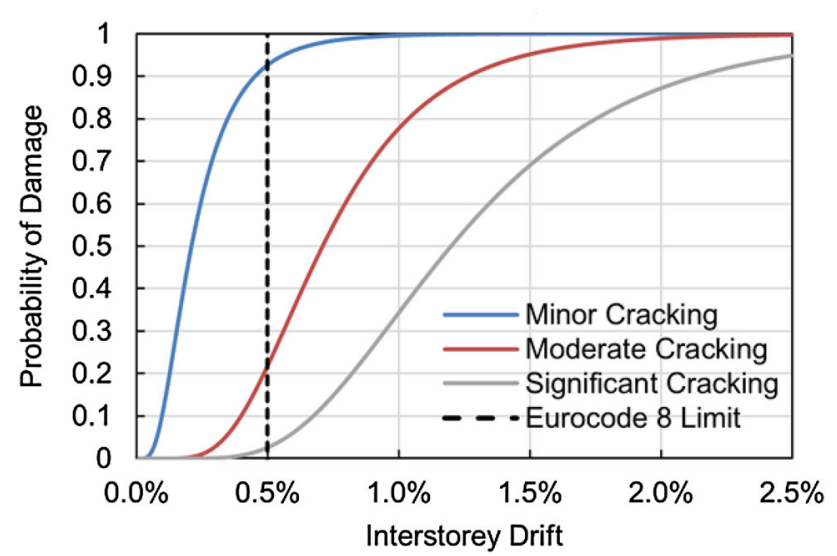

Fig. 11 Wall partition fragility functions and the Eurocode 8 drift limit for nonstructural protection

this finding using fragility functions for a gypsum wall partition. Damage states one, two, and three correspond to minor, moderate, and significant cracking respectively. If the $0.5 \%$ drift limit is respected, a wall partition is still expected to sustain damage. The probability of reaching damage state one is $93 \%$, while the probability of reaching damage state two is $22 \%$.

The nonstructural systems used in the case study are of the highest seismic design category in FEMA P-58. It is expected that the nonstructural repair costs would increase for buildings with more vulnerable systems. In addition to the drift-sensitive costs, extensive acceleration-sensitive nonstructural repair costs were also generated. Accelerations are only considered for calculations of anchorage strength in the Eurocode. These results highlight the need for further review of the Eurocode nonstructural provisions.

\section{Conclusion}

Achieving a seismic performance objective requires the coordination of structural and nonstructural performance. Recent earthquakes have revealed that conventional seismic design philosophy allows for large levels of nonstructural damage. An improved understanding of the nonstructural seismic performance of code-compliant buildings is therefore needed. This study assesses the seismic performance of a structural design that is characteristic of conventional multi-storey buildings constructed in seismic regions.

The FEMA P-58 procedure was used to determine the expected earthquake repair costs for a modern Eurocode CBF structure considering nonstructural systems. The seismic performance assessment of the conventional building design generated large repair costs for both the
SLS and ULS scenarios. These direct economic losses would be compounded by indirect costs due to downtime and disruptions. The performance assessment indicated it is probable that similar buildings designed to modern structural standards may be demolished and replaced following a ULS earthquake due to the high repair costs. The substantial repair costs for the SLS scenario were concerning because damage should be limited during this more frequent event. These results suggest that modern building standards do not accomplish earthquake resilience: the ability of a community to recover quickly after an earthquake. This benchmark of seismic performance is a novel research contribution. The results highlight that further research is needed in the area of total-building seismic performance for modern code-compliant structures.

Conventional structural codes control drifts but do not place limitations on accelerations. The classification of total repair costs by EDP is a novel contribution. It was observed that acceleration-sensitive damage is comparable to drift-sensitive damage for the case study building. The influence of acceleration on seismic performance should be more appropriately reflected in the design procedures of structures.

Limitations of the Eurocode damage mitigation methodology were revealed in a novel manner using FEMA P-58. The prescribed $0.5 \%$ drift limit to minimize nonstructural damage did not prevent the generation of large nonstructural repair costs. The nonstructural systems used in the case study are of the highest seismic design category-repair costs would increase for more vulnerable systems. Extensive acceleration-sensitive nonstructural repair costs were also generated, as accelerations are only considered in Eurocode 8 for calculations of anchorage strength. These results draw attention to the need for structural design procedures that enhance nonstructural seismic performance. This shift in seismic design philosophy is required in order to minimize the societal impacts of earthquakes and achieve a rapid return to building occupancy after an earthquake.

Fragility groups that significantly contribute to repair costs were identified as structural components, glass curtain wall cladding, wall partitions, suspended ceilings, HVAC equipment, and office equipment. Negligible costs were associated with stairs, access flooring, elevators, piping, fire sprinkler systems, and electrical systems. This novel finding will enable future seismic performance assessments to include only the fragility groups critical to repair costs in order to decrease computational effort.

The results of the seismic performance assessment provide a benchmark on which to evaluate alternative building designs. This benchmark is valuable when selecting retrofit alternatives for existing buildings and design options for new structures. The final aim of the 
project is to evaluate fluid viscous damper placement strategies that minimize nonstructural repair costs and building service disruptions. Fluid viscous dampers will be incorporated into the structures following the completion of additional benchmarks. The capability of fluid viscous dampers to improve nonstructural seismic performance will be assessed and damper placement optimization will be explored. Expectations are shifting in modern earthquake engineering, as clients are requesting performancebased design. This research contributes towards meeting these new expectations.

Open Access This article is distributed under the terms of the Creative Commons Attribution 4.0 International License (http://crea tivecommons.org/licenses/by/4.0/), which permits unrestricted use, distribution, and reproduction in any medium, provided you give appropriate credit to the original author(s) and the source, provide a link to the Creative Commons license, and indicate if changes were made.

\section{References}

ATC (Applied Technology Council). 2012. FEMA P-58 seismic performance assessment of buildings. Washington, DC: Federal Emergency Management Agency.

Black, R.G., W.A. Wenger, and E.P. Popov. 1980. Inelastic buckling of steel struts under cyclic load reversal. Berkeley: University of California Berkeley.

CEN (Comité Européen de Normalisation/European Committee for Standardization). 2010. Eurocode-basis of structural design. Brussels: European Committee for Standardization.

CEN (Comité Européen de Normalisation/European Committee for Standardization). 2013. Eurocode 8-Design of structures for earthquake resistance-Part 1: General rules, seismic actions and rules for buildings. Brussels: European Committee for Standardization.

Charney, F.A. 2008. Unintended consequences of modeling damping in structures. Journal of Structural Engineering 134(4): $581-592$.

CSI (Computers and Structures Inc.) 2013. SAP2000 V15.2.1. Berkeley: Computers and Structures Inc.

Dhakal, R.P. 2010. Damage to non-structural components and contents in 2010 Darfield earthquake. Bulletin of the New Zealand Society for Earthquake Engineering 43(4): 404-411.

Fierro, E.A., E. Miranda, and C.L. Perry. 2011. Behavior of nonstructural components in recent earthquakes. In Architectural Engineering Conference (AEI) 2011, 369-377. Oakland: American Society of Civil Engineers.

Miranda, E., G. Mosqueda, R. Retamales, and G. Pekcan. 2012. Performance of nonstructural components during the 27 February 2010 Chile earthquake. Earthquake Spectra 28(S1): 453-471.

PEER (Pacific Earthquake Engineering Research Center). 2013. PEER NGA-WEST 2 ground motion database. http://ngawest2. berkeley.edu/site. Accessed Sept 2016.

PEER (Pacific Earthquake Engineering Research Center). 2015. OpenSees V2.4.6. Berkeley: University of California Berkeley.

Solomos, G., A. Pinto, and S. Dimova. 2008. A review of the seismic hazard zonation in national building codes in the context of Eurocode 8. European Commission Joint Research Centre Scientific and Technical Reports. http://eurocodes.jrc.ec.europa. eu/doc/EUR23563EN.pdf. Accessed Sept 2016.

Taghavi, S., and E. Miranda. 2003. Response assessment of nonstructural building elements. Berkeley: Pacific Earthquake Engineering Research Center.

Uriz, P., F.C. Filippou, and S.A. Mahin. 2008. Model for cyclic inelastic buckling of steel braces. Journal of Structural Engineering 134(4): 619-628. 